\title{
Percepção de mães sobre o cuidado domiciliar prestado ao bebê nascido com baixo peso
}

\author{
Mothers' perception about homecare delivered to her low weight infant \\ Percepciones de madres acerca del cuidado domiciliar prestado al bebé nascido con bajo peso
}

\section{Elieth Lessa Fonseca', Sonia Silva Marcon ${ }^{1}$}

'Universidade Estadual do Paraná. Maringá, PR

Submissão: 09/07/2009

Aprovação: $20 / 1$ 1/2010

\section{RESUMO}

O objetivo do estudo foi identificar as dificuldades percebidas pelas mães no cuidado aos bebês de baixo peso e conhecer os recursos utilizados diante das intercorrências na saúde. Estudo de natureza Qualitativa, desenvolvido junto a seis mães residentes em Maringá, PR, Brasil. Os dados foram coletados no período de fevereiro a setembro de 2008, em Quatro visitas domiciliares, por meio de entrevista semi-estruturada. As mães vivenciaram dificuldades relacionadas aos profissionais e serviços de saúde, características do bebê, condições financeiras, alterações na rotina familiar e retorno ao trabalho. No enfrentamento das intercorrências, utilizaram recursos próprios ou atendimento médico. Concluiu-se que a mãe e a família necessitam de acompanhamento e apoio profissional para melhor cuidar do bebê de baixo peso no domicílio.

Descritores: Saúde da criança; Cuidado do lactente; Enfermagem pediátrica; Família; Recém-nascido de baixo peso; Pesquisa Qualitativa.

\section{ABSTRACT}

The purpose of the study was to identify problems perceived by mothers in caring of low birth weight babies and to understand the resources used while facing health complications. The Qualitative study was developed together with six mothers living in Maringá, PR, Brazil. Data were collected from February to September 2008 in four home visits through semi-structured interviews. The mothers experienced difficulties related to healthcare professionals and services, infant's characteristics, changes in family routine and the return to work. To confront the problems, they used their own resources or medical care. It was concluded that the mother and the family need professional monitoring and support to better care for the low birth weight baby at home.

Descriptors: Child health; Infant care; Pediatric nursing; Family; Infant, low birth weight; Qualitative research.

\section{RESUMEN}

El objectivo de este estudio fue identificar las dificultades percibidas por las madres en el cuidado de los bebés de bajo peso y conocer los recursos utilizados frente a las ocurrencias en la salud. Estudio de carácter cualitativo, desarrollado junto a seis madres Que vivem en Maringá, PR, Brasil. Los datos fueron recogidos en el periodo de febrero hasta septiembre de 2008, en cuatro visitas domiciliares, por medio de entrevistas semi-estructuradas y observación no sistematizada. Las madres vivenciaron dificultades relacionadas a los profesionales, servicios de salud, características del bebé, condiciones financieras, alteraciones en la rutina familiar y vuelta al trabajo. En el enfrentamiento de las ocurrencias utilizaron medios propios o la atención médica. Se concluy que la madre y la familia necesitan de acompañamiento y apoyo profesional para mejor cuidar del bebé con bajo peso en el domicilio.

Descriptores: Salud del niño; Cuidado del lactante; Enfermería pediátrica; Familia; Recién nacido de bajo peso; Investigación cualitativa.

AUTOR Sonia Silva Marcon. Universidade Estadual de Maringá. Av. Colombo, 5790. Jardim Universitário. CEP 87020-090.

CORRESPONDENTE Maringá, PR. E-mail: soniasilva.marcon@gmail.com 


\section{INTRODUÇÃO}

O baixo peso (BP) é responsável por dois terços do total de mortes neonatais, aQuelas ocorridas nos primeiros 27 dias de vida ${ }^{(1)}$. Ocasiona déficit motor, sensorial e dificuldade de aprendizagem ${ }^{(2)}$, como também internações durante grandes períodos em unidades de terapia intensiva neonatal (UTIN), com risco aumentado para morbimortalidade e comprometimento/atraso no desenvolvimento ${ }^{(3)}$.

O número elevado de neonatos de baixo peso ao nascimento (peso inferior a $2.500 \mathrm{~g}$, sem considerar a idade gestacional) constitui um importante problema de saúde e representa um alto percentual na morbimortalidade neonatal. Além disso, tem graves consequências médicas e sociais.

Diante dessa realidade, o atendimento perinatal tem sido foco primordial do Ministério da Saúde desde o início da década de 1980, sendo um dos seus pilares o Programa de Humanização do Pré-Natal e Nascimento, instituído em junho de 2000, Que tem como principal estratégia garantir a melhoria do acesso, da cobertura e da Qualidade do pré-natal e da assistência ao parto e ao puerpério. Esse programa amplia as ações já adotadas na área pelo Ministério da Saúde, como os investimentos nas redes estaduais de assistência à gestação de alto risco e o incremento do custeio de procedimentos específicos $^{(4)}$.

Considerando a evolução das políticas públicas para o cuidado da saúde da criança, reconhecemos Que houve esforços para assegurar Que os bebês, de forma geral, tenham seu crescimento e desenvolvimento acompanhados pelo setor de saúde e isto é enfatizado no caso de bebês Que sofreram alguma intercorrência ao nascimento, e o baixo peso é uma delas.

Em estudo realizado junto a oito famílias de crianças nascidas prematuras e com muito baixo peso (MBP) nos anos de 1998 a 2000 em Maringá-PR, verificou-se Que, apesar de seis delas terem sido consideradas prematuras extremas (PE) e terem ficado internadas na UTIN cerca de três meses, as famílias não tiveram garantia de atendimento com especialistas após a alta hospitalar ${ }^{(3)}$. Tal fato levou essas famílias a despenderam uma enorme Quantidade de tempo e energia física em busca de assistência e de esclarecimento de diagnóstico relacionado com algumas alterações e atrasos Que eram percebidas à medida Que as crianças cresciam e se desenvolviam. O cuidado a essas crianças ocorreu de maneira solitária, Quando, na verdade, estas famílias demonstraram a necessidade de um programa de acompanhamento multiprofissional, em Que seus filhos pudessem ser avaliados e cuidados com Qualidade, com todo suporte necessário e de forma a favorecer seu crescimento e desenvolvimento ${ }^{(5)}$.

Acredita-ses Que, para uma atuação junto a esses bebês e suas famílias, visando oferecer um atendimento integrado, faz-se necessário um cuidado Que atenda não apenas ao aspecto biológico, mas também ao emocional, sociocultural, econômico e político, passando pela garantia de acesso, equidade, adequações técnicocientíficas, bem como uma atuação efetiva em todos os elos da cadeia no atendimento a gestante e recém- nascido, incluindo o compromisso com a atenção interdisciplinar após sua alta ${ }^{(6)}$. Para isso, é fundamental o levantamento de problemas e estabelecimento de metas a serem alcançadas, priorizando o suporte a essas mães e famílias no enfrentamento das situações advindas do nascimento de uma criança de BP e as demandas decorrentes das necessidades de cuidado deste filho.

O contexto familiar e o ambiente em Que vive a criança têm uma influência marcante na sua recuperação e sobre seu processo de desenvolvimento. Em geral, a criança com necessidades especiais, Que foi assistida em uma UTIN, com equipe de especialistas e equipamento sofisticado, sofre um grande impacto ao chegar em casa. Muitas vezes, o ambiente domiciliar é completamente adverso e não possui infraestrutura suficiente para receber esta criança, além de ser uma experiência completamente desconhecida para a mãe, a cuidadora principal.

Diante do exposto o objetivo deste estudo foi identificar as dificuldades percebidas pelas mães no cuidado aos bebês de baixo peso e conhecer os recursos utilizados diante das intercorrências na saúde da criança.

\section{MÉTODOS}

Este é um estudo de natureza Qualitativa, desenvolvido em Maringá, PR, junto a seis mães de bebês nascidos com menos de $2000 \mathrm{~g}$ e Que receberam alta hospitalar no período de fevereiro à abril de 2008.

Para a inclusão no estudo, considerou-se o fato de os bebês terem nascido no hospital Que autorizou a realização da visita ainda durante a internação da criança e a possibilidade de alta até o mês de abril, de forma Que o acompanhamento pós alta hospitalar pudesse ser realizado por um período de seis meses sem comprometer o tempo definido para o termino do estudo.

Os dados foram coletados no período de fevereiro à setembro de 2008, por meio de entrevistas semiestruturadas em Quatro visitas domiciliares, realizadas em diferentes momentos: uma semana, um mês, três meses e seis meses após a alta hospitalar.

$\mathrm{O}$ instrumento utilizado durante as entrevistas foi um roteiro com Questões fechadas, abordando as características das famílias e seus bebês e três Questões norteadoras, as Quais foram repetidas em cada um dos encontros: "Como está sendo para vocês cuidarem do bebê aqui na sua casa?"; "Ocorreu alguma intercorrência?"; "O Que vocês fizeram diante dela?".

Para a análise das informações, adotou-se a técnica da análise de conteúdo, proposta por Bardin, de modo a descobrir o Que estava por trás de cada conteúdo manifesto, seguindo as fases de pré- análise, exploração do material e tratamento dos resultados ${ }^{(7)}$. Para tanto, as entrevistas foram transcritas na íntegra e submetidas a um processo de leituras sucessivas, buscando identificar os significados Que eram mais comuns e Que apareciam com maior frequência, inicialmente, em cada entrevista e, posteriormente, na comparação com aQueles Que emergiam nas demais entrevistas. Para os significados Que eram comuns, foi estabelecida uma codificação, denominada de unidade de significado.

Todo o material foi lido e relido várias vezes para confirmar as codificações já estabelecidas ou criar novas unidades de significado. As unidades de significado foram analisadas à luz das indagações propostas, sempre se reportando ao texto, e, convergiram em duas categorias temáticas.

As categorias temáticas e suas respectivas unidades de significado reproduzem, de maneira evidente, o Que foi expresso de modo explícito ou não, as contradições e a relação entre as unidades de significado, para a compreensão dos significados apreendidos, 
tomando por base os discursos das mães acerca das dificuldades para cuidar no domicílio e do enfrentamento de intercorrências na saúde do bebê nos seis primeiros meses após a alta hospitalar.

O desenvolvimento do estudo ocorreu em conformidade com as diretrizes da Resolução MS 196/96, após aprovação do projeto pelo Comitê Permanente de Ética em Pesquisa com Seres Humanos da Universidade Estadual de Maringá (Parecer no 220/2007)

Os contatos com as mães para solicitação da participação no estudo foram realizados logo após o nascimento do bebê, ainda no período de internação, por meio de visitas ao hospital ou por telefone logo depois da alta, momento em Que foram informados os objetivos do estudo e tipo de participação desejada. Todas as participantes assinaram o Termo de Consentimento Livre e Esclarecido em duas vias. Para assegurar o anonimato das mães participantes, estas foram identificadas por uma característica Que, em sua opinião, representasse o momento vivenciado de cuidar de um bebê nascido com BP. Ao lado do nome escolhido pela mãe, foram acrescentados a posição do membro na família, a letra $\mathrm{E}$ e um número referente à seQuência dos encontros.

\section{RESULTADOS E DISCUSSÃO}

\section{Conhecendo as famílias e seus bebes}

No Quadro 1 estão apresentadas algumas características das famílias em estudo. Observa-se Que a maioria dos pais são jovens e possuem baixa escolaridade. Em relação aos bebês, os três Que nasceram com mais baixo peso, foram os Que permaneceram mais tempo internados, inclusive na UTI.

A vivência da mãe ao cuidar do filho nascido com BP no domicílio durante os seis primeiros meses após a alta hospitalar revelou ser permeada por desafios e decisões e nesta comunicação é apresentada parte desta experiência reunida em duas categorias: Dificuldades para cuidar e Enfrentando intercorrências na saúde do bebê.

\section{Dificuldades para cuidar}

Ir para a casa com um bebê de BP, segundo as mães em estudo, trouxe dificuldades, independente do contexto de vida, experiências anteriores ou idade dos pais. A cada encontro, surgiam os relatos de situações difíceis Que estavam sendo vivenciados naquele momento ou mesmo anteriormente, decorrentes dos diversos fatores relacionados com os cuidados ao bebe BP. As dificuldades referidas envolveram Questões relacionadas aos profissionais e serviços de saúde, às características do bebê, alterações na rotina familiar e retorno ao trabalho.

No primeiro encontro, aquele realizado uma semana depois da alta hospitalar, a dificuldade referida com maior freeuência foi relacionada aos serviços e profissionais de saúde, porque nesse período, algumas famílias estavam tentando realizar as consultas especializadas e retornos indicados na alta hospitalar. A alta hospitalar, por exemplo, é um momento muito esperado pelas famílias e que deve ser planejado pela equipe de saúde durante o período de internação, porém uma das mães não vivenciou essa realidade.

O médico que tratou dela estava de folga Quando eu recebi alta, então foi outra médica Que liberou...ela não deu prá mim nenhuma explicação... não recebi instrução nenhuma. Foi isto Que aconteceu, e faz falta. (Mãe da Família Carinho-EI)

\begin{tabular}{|c|c|c|c|c|c|c|c|c|}
\hline \multirow[b]{2}{*}{ Família } & \multicolumn{2}{|c|}{ Características dos pais } & \multicolumn{4}{|c|}{ Características da família } & \multicolumn{2}{|c|}{ Características do bebê } \\
\hline & $\begin{array}{c}\text { Idade do } \\
\text { pais }\end{array}$ & $\begin{array}{c}\text { Grau de } \\
\text { instrução }\end{array}$ & Religião & $\begin{array}{l}\mathrm{n}^{\circ} \\
\text { filhos }\end{array}$ & $\begin{array}{c}\text { Renda } \\
\text { familiar }\end{array}$ & Moradia & $\begin{array}{c}\text { Condições de } \\
\text { nascimento }\end{array}$ & $\begin{array}{l}\text { Tempo de } \\
\text { internação }\end{array}$ \\
\hline Atenção & $\begin{array}{l}\text { Pai }-52 \\
\text { Mãe - } 40\end{array}$ & $\begin{array}{l}\text { Pai - Ensino médio } \\
\text { Mãe - Analfabeta }\end{array}$ & Evangélica & 8 & $\mathrm{R} \$ 1.500,00$ & alugada & $\begin{array}{l}P=1.675 g \\
I G-33 \text { sem } \\
\text { Apgar - I e } 7\end{array}$ & $\begin{array}{c}57 \text { DIAS } \\
20 \text { na UTIN }\end{array}$ \\
\hline Apoio & $\begin{array}{c}\text { Pai - } 36 \\
\text { Mãe - } 33\end{array}$ & $\begin{array}{l}\text { Pai - Ens. } \\
\text { Fundamental } \\
\text { Mãe - Ens. } \\
\text { Fundamental }\end{array}$ & Católica & 3 & $\mathrm{R} \$ 800,00$ & cedida & $\begin{array}{l}P=1.225 g \\
I G-33 \text { sem } \\
\text { Apgar - } 7 \text { e } 9\end{array}$ & $\begin{array}{c}33 \text { dias } \\
15 \text { na UTIN }\end{array}$ \\
\hline Carinho & $\begin{array}{c}\text { Pai }-41 \\
\text { Mãe - } 40\end{array}$ & $\begin{array}{c}\text { Pai - Ens. Superior } \\
\text { Mãe - Ens. } \\
\text { Superior }\end{array}$ & Católica & 2 & $\mathrm{R} \$ 2.000,00$ & própria & $\begin{array}{c}P=1.900 g \\
I G-33 \text { sem } \\
\text { Apgar }-6 \text { e } 9\end{array}$ & $\begin{array}{c}12 \text { dias } \\
2 \text { na UTIN }\end{array}$ \\
\hline Alegria & $\begin{array}{c}\text { Pai }-33 \\
\text { Mãe - } 28\end{array}$ & $\begin{array}{l}\text { Pai - 4a Série } \\
\text { Mãe - Ens. } \\
\text { Superior }\end{array}$ & $\begin{array}{l}\text { evangélica } \\
\text { / católica }\end{array}$ & 2 & $\mathrm{R} \$ 3.000,00$ & própria & $\begin{array}{l}P=1.880 g \\
I G-33 \text { sem } \\
\text { Apgar - } 7 \text { e } 9\end{array}$ & $\begin{array}{l}11 \text { dias } \\
4 \text { na UTIN }\end{array}$ \\
\hline Amor & $\begin{array}{c}\text { Pai }-45 \\
\text { Mãe }-4 \text { I }\end{array}$ & $\begin{array}{l}\text { Pai - Ens. } \\
\text { Fundamental } \\
\text { Mãe - Ens. } \\
\text { Fundamental }\end{array}$ & Evangélica & 5 & $\mathrm{R} \$ 2.000,00$ & própria & $\begin{array}{c}P=1.920 g \\
I G-33 \text { sem } \\
\text { Apgar }-8 \text { e } 10\end{array}$ & $\begin{array}{c}8 \text { dias } \\
3 \text { na UTIN }\end{array}$ \\
\hline $\begin{array}{c}\text { Esperanç } \\
\mathrm{a}\end{array}$ & $\begin{array}{c}\text { Pai }-25 \\
\text { Mãe }-22\end{array}$ & $\begin{array}{l}\text { Pai - Cursando } \\
\text { Supletivo } \\
\text { Mãe -Cursando } \\
\text { Supletivo }\end{array}$ & Católica & 1 & $R \$ 600,00$ & cedida & $\begin{array}{l}P=1.330 g \\
I G-33 \text { sem } \\
\text { Apgar }-3 \text { e } 7\end{array}$ & $\begin{array}{c}63 \text { Dias } \\
13 \text { na UTIN }\end{array}$ \\
\hline
\end{tabular}

$P=$ peso; $I G=$ idade gestacional e Apgar = apgar no $I^{\circ}$ e $5^{\circ}$ minuto

Quadro 1. Características dos pais, das famílias e dos bebês em estudo. Maringá, PR, 2008. 
Demonstrando o reconhecimento pela importância do preparo para alta, o relato enfático da mãe destaca não só a ausência do profissional Que estava acompanhando seu bebê durante o internamento, bem como a ausência das orientações para sua alta, referindo-se como algo Que deveria existir e Que sentiu falta. Considerando o acesso e o tempo de cuidado que a enfermagem deveria ter com essa mãe durante o período de internação, possibilita-nos refletir Quão distante esteve, já Que, infelizmente, não foi mencionada nenhuma ação nesse momento.

Concordamos Que cada profissional envolvido deve estar atento para oferecer atendimento integral à criança dentro do contexto da família e da sociedade. Cada um deve procurar articular sua ação com a de outros profissionais, não perdendo oportunidades de atuação para promoção, prevenção e assistência ${ }^{(8)}$. O acompanhamento, ao ser realizado, precisa levar em conta o contexto do cuidado e a relação de confiança existente entre parturiente e profissional, influenciando, positivamente, a Qualidade dos sentimentos dessa mãe como também uma adaptação saudável ao seu novo papel, o Que poderia amenizar suas dificuldades ${ }^{(9)}$.

A dificuldade referida em relação aos profissionais de saúde esteve Quase sempre relacionada a uma percepção de despreparo dos mesmos para atender recém-nascidos com baixo peso.

Elas (pessoal da enfermagem) não sabem como lidar, não sabem o risco. A neném não tem vacina ainda, só depois de dois Quilos, né? Eu não podia ficar ali no meio daquele monte de gente tanto tempo... Eu não sei se elas têm aqueles cursos de reciclagem, porQue o mundo é um lugar globalizado [...]. Elas têm Que aprender como lidar com este tipo de bebê... (Mãe da Família Carinho-EI)

Nesse momento, ao mesmo tempo, a mãe aparentava tristeza e indignação Quanto ao atendimento recebido na Unidade Básica de Saúde, pela equipe de enfermagem. Para ela, a equipe precisa de preparo e o acompanhamento no período pós-natal precisa ser melhorado. Sendo assim, é imprescindível que a enfermagem assuma seu papel no atendimento do ciclo gravídico puerperal, mediante uma interação efetiva, o Que diminuiria o descontentamento e a insegurança para o desenvolvimento do papel materno ${ }^{(10)}$.

Além da equipe de enfermagem, a mãe da família Carinho também referiu dificuldades Quanto ao atendimento de saúde especializado, mencionando o longo tempo de espera das consultas para o bebê de BP.

E até é assim prá gente agendar um neuro, uma fono, um oftalmologista ou fisioterapeuta, tem Que fazer encaminhamento de tudo, e só daqui a uns dois ou três meses. E mesmo você explicando que é um caso especial, eles falam que não dá prá fazer nada.. (Mãe da Família Carinho-E I)

Observa-se Que esta mãe está comprometida com o acompanhamento do bebê após a alta, seguindo as orientações dos profissionais do hospital, porém, se depara com o tempo de espera para o atendimento e o considera demasiadamente longo diante de uma necessidade Que percebe como imediata. Podemos apreender Que a mãe vivencia uma controvérsia entre o Que recebe de orientação no hospital Quanto aos serviços Que deve procurar e o Que é oferecido na atenção básica. Com este descompasso, impõese repensar o cuidado desses bebês nas unidades de saúde para um acompanhamento de Qualidade, permitindo primeiramente o acesso, no Qual a comunicação e o relacionamento humano sejam valorizados, para proporcionar um cuidado integral ao bebê, à mãe e à família ${ }^{(8,11)}$. As mães também fizeram referência a algumas características próprias do bebê de BP como o sono prolongado.

[...] mexer, arrancar a roupa, mesmo assim é triste! Então, eu tenho Que por ela prá mamar dormindo mesmo! Às vezes, passa da hora [... I não é fácil, por isso tenho que ficar por conta dela!. (Mãe da Família Amor-El)

Dormir por períodos prolongados, uma sucção débil ou atividade motora diminuída dificulta a alimentação do bebê, sendo necessária a insistência da mãe e a dedicação por maior tempo. Esta situação pode contribuir para o aumento da ansiedade, comum à essa fase inicial de cuidados com o bebê, podendo gerar na mãe sentimento de impotência por não conseguir, por exemplo, amamentar o bebê. Em estudo com mães Que verbalizaram fatores Que influenciam o aleitamento de bebês de baixo peso, se encontram, entre outros, as características comportamentais desse bebê $\hat{e}^{(12)}$.

A maioria das mães, com o passar do tempo foi conseguindo superar as dificuldades relacionadas às características do bebê, porém a mãe da Família Amor, apesar de ser mais velha e já ter cuidado de outros filhos, no terceiro encontro, ainda referiu Que continuava com dificuldades nesta área.

Tudo é complicado prá mim nesse bebê, tudo, tudo é difícil, parece que eu nunca tive filho, parece que esse é o primeiro. (Mãe da Família Amor-E3)

Ao fazer uso da expressão "tudo é complicado... nesse bebê", essa mãe revela a singularidade de sua experiência e, ao mesmo tempo desmistifica a presença de experiências anteriores. Sua dificuldade de cuidar pode estar relacionada, por exemplo, ao longo tempo Que precisa dispender para esse cuidado, acrescido da concepção de Que seu bebê é um ser muito frágil ${ }^{(13)}$.

Outras dificuldades Que foram percebidas pelas famílias com a chegada do bebê no domicílio foram as alterações nas rotinas familiares como, por exemplo, o aumento das tarefas domésticas, percebidas pelas mães da Família Apoio e Carinho, como a causa de um repouso inadequado Que influencia a produção do leite ou a sua recuperação da cirurgia.

É difícil de ficar tranquila e poder descansar para ter o leite, não tenho muito tempo.., sair, levar e buscar na escola esse menino mais velho. Na hora de buscar, tem Que estar na hora certinho, não pode passar um minuto, porQue é bastante perigoso! (Mãe da Família Apoio-E I)

Eu tentei ficar um dia em casa deitada por causa da minha dieta, sabe? Mais aí eu não consigo ter aQuela tranQuilidade prá guardar a dieta. PorQue daí tem Que lavar, fazer almoço, uma roupa, sabe? Daí não dá tempo. (Mãe da Família Carinho-El)

Quanto às alterações na rotina da família, estas foram men- 
cionadas até por ocasião do Quarto encontro, Quando a mãe da Família Carinho relata sua dificuldade em realizar algumas atividades.

E eu Quase não tô saindo [...] às vezes, eu venho prá casa da minhamãe, prá um mercado, ou coisa assim. Não voltei a ter vida socialainda, sabe. Na igreja, só vou e volto, não tô participando [...] eu tôsentindo muita falta disso [...]. E isto é o Que tá me fazendo mais falta, é isso ai . (Mãe da Família Carinho-E4)

A restrição das atividades rotineiras, em particular o retorno à vida social, foi mencionada pela mãe como algo Que sente falta, aparentando o desejo de retomar o Quanto antes. Nesse caso, percebemos Que a mãe é o membro da família Que sofre o maior impacto das alterações na rotina, Que, possivelmente, nunca mais será a mesma, sendo compreensível a demonstração do sentimento de perda da liberdade.

Esse sentimento foi relatado também por mães adolescentes como algo ruim, devido à maternidade precoce, considerando difícil o fato de não poderem realizar as atividades Que eram comuns anteriormente ao nascimento do bebê $\hat{e}^{(13-14)}$.

Além de dificuldades com profissionais, serviços e características do bebê, foram mencionadas dificuldades relacionadas ao retorno ao trabalho, sendo Que a mãe da Família Esperança decidiu permanecer em casa cuidando do filho por um período, mas refere dificuldade financeira.

Eu tô Querendo muito trabalhar... Às vezes, eu Quero comprar alguma coisa pra mim ou prá ele e não tem como, sabe? O mais difícil é isso, porQue minha vida já voltou tudo ao normal com ele. (Mãe da Família Esperança-E3)

lá a mãe da Família Alegria, considera muito difícil, o retorno ao trabalho após a licença maternidade, já Que, mesmo com o apoio familiar, foi preciso adeQuar a rotina de trabalho e inclusive mudar de emprego.

Olha, foi muito difícil o período que eu voltei a trabalhar. Tudo ficava muito longe, meu emprego, a casa da minha mãe, onde ela ficava parte do dia, e a escolinha. Então ficava o dia todo sem ver ela, porQue às vezes na hora do almoço eu ia na escolinha e ela estava dormindo, eu ficava com dó de acordar ela. À noite, ela Queria só meu colo. Eu não podia fazer nada, Que ela chorava de gritar. Daí, eu saí daeuele emprego, agora, estou trabalhando com meu marido e fica tudo pertinho, então, ela está mais calma, deu prá ver a diferença. (Mãe da Família Alegria-E4)

Observa-se Que tanto permanecer em casa, como retornar ao trabalho foi considerado pelas mães uma dificuldade, pois na primeira situação a mãe fica privada de conseguir tudo Que deseja, porém a segunda mãe refere à dificuldade de estar afastada da filha e a sobrecarga no seu dia a dia.

O fato de fazer opção de cuidar do filho em casa se iguala aos relatos de estudos ${ }^{(13-14)}$ com mães adolescentes, em Que as mesmas revelaram deixar em segundo plano outras atividades para cuidar do filho. Todavia, nos estudos citados, não houve referências a dificuldades advindas dessa opção. Porém, mães professoras também consideram o retorno ao trabalho um momento difícil,
porQue além de esposa e profissional, agora exerce o papel de mãe de um bebê, sofre pela distância do filho e passa por momentos de ansiedade e preocupação(15).

\section{Enfrentando intercorrências na saúde do bebê}

Ao deixar o hospital, a mãe passa por um período de transição, saindo de um ambiente tecnológico com especialistas no cuidado do bebê para seu contexto de vida no domicílio. Em casa, a mãe vivencia uma série de desafios para manter o bebê em boas condições de saúde, além de enfrentar intercorrências Que vão desde alguns Quadros leves, como, por exemplo a cólica e a secreção ocular, até outros Quadros graves Que exigem inclusive internação na Unidade de Tratamento Intensivo Pediátrico (UTIP).

Uma das mães, logo Que chegou à sua casa, já se deparou com uma situação Que a preocupou bastante, uma vez Que não tinha conhecimento da causa do problema, voltou para o hospital.

Mas quando eu cheguei em casa que eu vi a temperatura dela, nossa! Ela tava com febre. (mãe chora) Voltei no Pronto Socorro, fiz todos exames, só saí de lá Quase de noite! (Mãe da Família Amor-El)

Percebe-se Que a febre é percebida pela mãe da Família Amor como uma intercorrência muito grave, visto Que, só a lembrança do ocorrido, deixou a mãe com os olhos marejados, demonstrando a angústia e o medo Que esta intercorrência desencadeou, pela possibilidade do bebê vir a ter alguma complicação. Esta situação é compreensível, por ainda ser recente a dolorosa experiência de uma gravidez de risco, parto antecipado e a passagem do bebê por três dias na UTIN.

A mãe da Família Alegria experienciou a mesma intercorrência em duas ocasiões e o relato das mesmas ocupou boa parte do tempo no primeiro e segundo encontros, já Que elas desencadearam muito estresse para a mãe.

Ela engasgou de novo, mas não ficou roxinha, ficou vermelhinha, voltou pelo nariz também e parece Que não podia respirar [...] Eu fieuei assustada, hein? Chupei o narizinho! Chupei a boca [...], fiz, mas fieuei morrendo de medo. (Mãe da Família Alegria-E2)

O enfrentamento de intercorrência na saúde faz parte do contexto de vida da família e encontra-se intimamente relacionado com a experiência de criar os filhos ${ }^{(16)}$. Observa-se no relato da mãe da Família Alegria Que, apesar da insegurança em não saber como agir diante de uma intercorrência considerada grave, em seu desespero, lançou mão de uma atitude intuitiva, ou seja, reagiu de acordo com o significado Que a situação tinha para ela e continuou alerta ${ }^{(17)}$.

Porém, diante de uma anormalidade considerada sem gravidade, como por exemplo, a presença de peQuena Quantidade de secreção purulenta na região do canal lacrimal, a mãe da Família Carinho manifestou seu desejo de resolver o problema sem evidenciar angústia ou preocupação. Neste caso, a solução encontrada foi aguardar o tempo de carência do plano de saúde para, então a, criança ser atendida pelo mesmo, especialmente porque, no momento, a família se encontrava com dificuldades financeiras. Se o problema fosse percebido pela mãe como grave, a opção seria buscar assistência na UBS. 
Ela está com um negocinho amarelinho no olho, e se Quiser ver esta semana, aí tem Que pagar uma consulta ou esperar o plano de saúde porQue a gente não está podendo gastar agora. (Mãe da Família Carinho-EI)

Os bebês, normalmente, estão sujeitos a apresentar várias alterações em sua saúde ou mesmo em seu bem-estar nos primeiros meses de vida, e a cólica é uma das mais citadas. Algumas famílias, inclusive, revelaram terem se incomodado diariamente com a mesma na primeira semana do bebê em casa. Esta, no entanto, parece ser uma alteração de certa forma esperada e, por esta razão, as famílias não demonstraram muita dificuldade em seu enfrentamento.

Agora nesses últimos dias, está tendo cólica, só Quer colo... (Mãe da Família Esperança-El)

Toda tarde, Quando é lá pelas sete horas ela tem cólica e Quer ficar no peito... (Mãe da Família Alegria-EI)

Por ocasião do segundo encontro, as famílias Alegria e Esperança continuaram a referir a presença de cólica, enQuanto Que, para as famílias Carinho e Amor, as manifestações desta intercorrência estava começando.

Acho Que ela está com cólica. Olha só o jeito dela! É ela fica assim nervosinha, meio vermelhinha [...] Mas, às vezes, ela só fica resmungando, se contorcendo um pouquinho, daí ela faz cocô já pára. Para melhorar, é mornar a fralda e colocar na barriguinha dela ou só um pouQuinho de chá. A médica falou, se ela estiver chorando muito, é prá dar duas gotinhas de tilenol na línguinha dela. (Mãe da Família Amor-E2)

Ela estava com muita cólica, aí a cólica melhorou muito depois Que começou com os supositórios. (Mãe da Família Carinho-E2)

Conforme relatos das mães, observamos, em todos os casos, Que, os modos de enfrentamento, Quase sempre, envolveram o uso de práticas alternativas de forma isolada ou associada ao tratamento medicamentoso. O enfrentamento das cólicas não foi considerado pelas famílias uma situação grave e Que exigia urgência, porém foi atendida com atenção e dedicação, representada por maior tempo junto ao bebê, provocando alteração da rotina e o desgaste físico principalmente das mães.

[...] às vezes, ela está com dor, com cólicas, mas não chega a chorar de dor assim [...] ela fica gemendo, incomoda Que ela encolhe [... J a pediatra disse Que é cólica de nenê mesmo. Posso fazer massagem, chazinho, passar uma fralda Quente com ferro, né? Ai boto ela de bruço, se não resolver mesmo, aí eu dou remédio. Às vezes, ela chora e toma muito tempo, porQue tem Que ficar com ela andando pela casa... (Mãe da Família Alegria-E2)

As cólicas são comuns nessa idade, constituindo-se uma das principais Queixas das mães e familiares durante a consulta de enfermagem, podendo ser uma intercorrência Que desaparece por si só, outras vezes necessita de acompanhamento do serviço de saúde para ser resolvida, com utilização de métodos alternativos ou medicamentos Que proporcionem o alívio da dor ${ }^{(18)}$.

A partir do segundo encontro, algumas vezes, as famílias mencionaram o drama vivido com o choro contínuo do bebê. Como havia dúvidas, a mãe utilizou o plano de saúde para confirmação do diagnóstico.

Eu levei ela no posto e o médico falou Que era manhã. Falei: não, manha, tudo bem, tem um pouco, mas o nenê gritar assim, isso não é manhã, não! Aí, não sabia o Que era, né? Daí, fez exame pelo plano e deu refluxo. Agora melhorou. Tá bem com o remédio. (Mãe da Família Amor-E2)

Diante dos relatos das mães com relação ao choro do bebê, ficou evidente Que esta é uma alteração Que chama a atenção das mesmas, gerando angústia e a busca de ajuda profissional. Nesse caso, o choro era demonstrativo de uma alteração importante Que merecia toda atenção, visto Que o bebê nascera de BP. O choro deve ser avaliado cuidadosamente, já Que as causas podem ser variadas, levando a condutas diversificadas. Sendo assim, é muito importante Que os profissionais de saúde dêem atenção aos pais, ouvindo suas Queixas e a verbalização de seus sentimentos, com uma postura de escuta e compreensão das necessidades da família e do bebê $\hat{e}^{(19)}$.

Durante o segundo encontro, outras alterações foram percebidas pelas mães, relacionadas ao padrão de sono do bebê e a problemas respiratórios. No Que se refere ao padrão de sono, as famílias perceberam duas situações diferentes: a criança com dificuldades para dormir tanto de dia como à noite.

Porque assim, ela demora prá dormir durante o dia, fica três Quatro horas acordada [...] porque nenê, geralmente dorme bastante. Mas eu vejo que ela tem dificuldade pra dormir, né? Às vezes, à noite também. Mesmo Que eu pegue ela no colo, ela não dorme. A pediatra pediu prá dar o banho mais de tarde, mais à noite. PorQue ela relaxa, e dorme. (Mãe da Família Alegria-E2)

E a criança trocando o dia pela noite: Eu dou banho nela cinco horas da tarde, pra ver se ela muda porque ela dorme o dia inteiro e de noite fica acordada! Se tem um reflexo de luz ela fica procurando, Quer colo, daí fica olhando ah ah ah... Meu Deus do Céu! (Mãe da Família Amor-E2)

Nos dois casos, a situação é de estresse, a Qual prejudica o descanso noturno dos pais e, em especial das mães, alterando toda a rotina diária. Quanto aos problemas respiratórios, as mães citaram desde pequenas intercorrências, como nariz congestionado, até intercorrência muito grave, como a pneumonia Que, por duas vezes, levou o bebê da Família Atenção à permanecer na UTIP por alguns dias. Segundo relato da mãe, por ocasião da segunda internação, a pediatra informou Que a criança estava com perda significativa de peso e fez novamente as orientações a esse respeito.

Pelos relatos das mães, pode-se identificar Que as mesmas experienciaram duas situações distintas em relação às intercorrências: as Que foram vividas com tranфuilidade, como, por exemplo, as cólicas e secreção ocular, e as Que foram entendidas como perigosas, gerando preocupação e medo, Que, inclusive, desencadearam a necessidade de buscar cuidados profissionais. Entre estas se encontram a hiperter- 
mia, engasgo, choro contínuo e pneumonia.

A percepção e diferenciação pela mãe entre o Que é perigoso, duvidoso ou conhecido é bastante complexo e faz parte da vivência de criar filhos, mas, nos casos de bebês baixo peso, estas situações são vivenciadas com maior frequência e de maneira mais intensa, por isso o desgaste é maior.

Os diferentes modos de enfrentamento das intercorrências pelas mães, bem como suas narrativas revelaram Que a Questão Que move seu agir está diretamente relacionada ao conhecimento. Ou seja, se a situação já foi experienciada pela mãe, família ou por alguém de suas relações, é enfrentada com mais traneuilidade, mas, se acontece algo desconhecido, a mãe demonstra seus medos e preocupações. A situação reconhecida pela enfermagem poderia criar um espaço de aproximação e atuação efetiva desses profissionais para o desenvolvimento de uma verdadeira enfermagem familiar.

\section{CONSIDERAÇÕES FINAIS}

Cada mãe, a seu modo e de acordo com os recursos disponíveis, enfrentou seus próprios desafios, sem uma noção exata do Que vivenciaria. Para o enfrentamento das intercorrências na saúde dos bebes, lançaram mão da experiência anterior, das orientações de familiares e do atendimento profissional. Cabe salientar que as mães reconhecem algumas manifestações de alterações como próprias do desenvolvimento infantil e por isto a sua presença não é interpretada como uma situação de perigo, outras porém, como a presença de hipertermia, choro contínuo e engasgo, são experienciadas com grande temor e por esta razão constitui motivo para a procura de ajuda profissional.

Os resultados encontrados mostram a importância de um acompanhamento mais amiúde por parte dos profissionais de saúde Quanto ao preparo das mães para o cuidado domiciliar, de modo não só a instrumentalizar as mães para o enfrentamento de intercorrências, mas também para tranquiliza-las Quanto ao desenvolvimento do filho. Este acompanhamento poderá inclusive, interferir positiva-mente na manutenção do aleitamento materno por mais tempo, visto Que o estado emocional da mãe é um dos fatores Que interfere nesta prática.

\section{REFERÊNCIAS}

I. Souza LR. Perinatologia atual. [online]. [citado em 2007 Jul 17]. Disponível em: http://www.jakobi.com.br/ obs0 I.htm

2. Silva OPV. A importância da família no desenvolvimento do bebê prematuro. Psicol Teor Pratic 2002; 4(2): 15-24.

3. Arruda DC, Marcon SS. Experiência da família ao conviver com sequelas decorrentes da prematuridade do filho. Rev Bras Enferm 2010; 63(4): 595-602.

4. Ministério da Saúde (BR). Secretaria de Políticas de Saúde. Área de Saúde da Criança. Atenção humanizada ao RN de baixo peso: método mãe canguru: manual do curso. Brasília: Ministério da Saúde; 2009.

5. Rugolo LMSS. Growth and developmental outcomes of the extremely preterm infant. J Pediatr 2005; 8 I (supl): I01-10.

6. Carvalho M, Gomes MA. A mortalidade do prematuro extremo em nosso meio: realidade e desafios. J Pediatr 2005; 8 I (supl I): SI I I-8.

7. Bardin L. Análise de conteúdo. Lisboa: Edições 70; 1977.

8. Ministério da Saúde (BR). Secretaria de Políticas de Saúde. Área de Saúde da Criança. Agenda de compromisso para a saúde integral e redução da mortalidade infantil. Brasília: Ministério da Saúde; 2004.

9. Rodrigues DP, Montesuma FG. Contribuição social dos formandos na assistência de enfermagem à mulher no pré-parto, parto e puerpério. Enferm Atual 2003; 3(I3): 32-6.

10. Rodrigues DP, Fernandes AFC, Silva RM, Rodrigues MSP. O domićlio como espaço educativo para autocuidado de puérperas: binômio mãe-filho. Texto Contexto Enferm 2006; 15(2): 277-86.

11. Tronchin DMR, Tsunechiro MA. A experiência de tornarem-se pais de prematuros: enfoque etnográfico. Rev Bras Enferm. 2005; 58(1): 49-54.
12. Padovani FHP. Indicadores emocionais de ansiedade, disforia e depressão e verbalizações maternas acerca do bebê, da amamentação e da maternidade em mães de bebês nascidos pré-termo de muito baixo peso, durante a hospitalização do bebê e após a alta, comparadas a mães de bebês nascidos a termo [tese]. Ribeirão Preto: Departamento de Psicologia e Educação, Universidade de São Paulo; 2005.

13. Trindade RF. Entre o sonho e a realidade: a maternidade na adolescência sob a ótica de um grupo de mulheres da periferia da cidade de Maceió-Alagoas [tese]. Ribeirão Preto: Escola de Enfermagem de Ribeirão Preto, Universidade de São Paulo; 2005.

14. Bergamaschi SFF. A vivência da puérpera-adolescente com o recém-nascido, no domicílio [dissertação]. São Paulo: Escola de Enfermagem, Universidade de São Paulo; 2007.

15. Gravena AC. Retorno ao trabalho após o nascimento de um filho: percepções de professoras sobre sua experiência [dissertação]. São Carlos: Universidade Federal de São Carlos; 2006.

16. Marcon SS, Elsen I. Os caminhos Que, ao criarem seus filhos, as famílias apontam para uma enfermagem familial. Ciênc Cuid Saúde 2006; 5(supl): I I-8.

17. Merighi MAB, Gonçalves R, Rodrigues IG. Vivenciando o período puerperal: uma abordagem compreensiva da Fenomenologia Social. Rev Bras Enferm 2006; 59(6): 775-9.

17. Silva LR, Moreira MC, Castro SI, Ribeiro F. A prática do cuidado prestado pelas mulheres aos filhos no domicílio. Enferm Global 2007; 6(10). Disponível em: http://revistas.um.es/eglobal/ article/view/207/244

18. Boehs AE. Recém-nascido. In: Verdi M, Boehs AE, Zampieri MFM, organizadores. Enfermagem na atenção primária de saúde. Florianópolis: Imprensa Universitária;. 2005. p. 215 42. 